\title{
Caracterização geológica, geomorfológica e evolutiva holocênica do litoral sul de Jaguaruna, SC, Brasil
}

\author{
Renato A. LEAL ${ }^{1}$ \& Eduardo G. BARBOZA ${ }^{2}$
}

1 Programa de Pós-Graduação em Geociências, Instituto de Geociências, Universidade Federal do Rio Grande do Sul. Av. Bento Gonçalves, 9500, CEP 91.540-000, Porto Alegre, RS, Brasil (relealsc@gmail.com).

2 Centro de Estudos de Geologia Costeira e Oceânica, Instituto de Geociências, Universidade Federal do Rio Grande do Sul. Av. Bento Gonçalves, 9500, CEP 91.540-000, Porto Alegre, RS, Brasil (eduardo.barboza@ufrgs.br).

Recebido em 05/2016. Aceito para publicação em 11/2017.

Versão online publicada em 16/3/2018 (www.pesquisasemgeociencias.ufrgs.br)

\begin{abstract}
Resumo - Compreender os processos evolutivos que ocorreram para a conformação atual do ambiente costeiro é de suma importância para estudos relacionados ao planejamento e gestão do litoral. 0 presente trabalho tem como objetivo caracterizar a barreira costeira holocênica do setor sul de Jaguaruna, Santa Catarina, do ponto de vista geológico, geomorfológico e evolutivo, através de dados de superfície e de subsuperfície, a fim de subsidiar a gestão costeira da região. 0 estudo foi realizado com base na interpretação de fotografias aéreas e na análise de dados geofísicos obtidos com um GPR. Em superfície foram identificados quatro depósitos sedimentares compondo a barreira costeira: Depósito Lagunar Praial, Depósito Paludial, Depósito Eólico e Depósito Marinho Praial. Do ponto de vista geomorfológico, esses depósitos se apresentam na forma de planície de cordões litorâneos, banhados, dunas e praia, respectivamente. Além destes, cristas de precipitação e paleocanais se destacam na morfologia da barreira. Quanto às informações de subsuperfície, a principal observação está relacionada à influência do Rio Urussanga sobre o ambiente marinho raso e praial durante a evolução da barreira. A presença de paleocanais em subsuperfície, juntamente com outras informações identificadas em superfície, permitiram caracterizar o comportamento evolutivo da barreira como regressiva. As seções de GPR possibilitaram identificar os paleocanais devido à presença de uma superfície erosiva em forma côncava, com alta amplitude e continuidade lateral. Acima dessa superfície ocorre o preenchimento dos paleocanais em fases distintas. Estas informações de caráter geológico e geomorfológico têm implicações importantes para o planejamento e gestão territorial.
\end{abstract}

Palavras-chave: Barreira holocênica, Paleocanal, Radar de Penetração de Solo, SIG.

\begin{abstract}
GEOLOGICAL, GEOMORPHOLOGICAL AND EVOLUTIONARY HolOCENE CHARACTERIZATION OF THE SOUTHERN COASTAL OF JAGUARUNA, SC, BRAZIL. Understanding the evolutionary processes that occurred for the current conformation of the coastal environment is very important for studies related to the planning and coastal management. This study aims to characterize the Holocene coastal barrier at the southern sector of Jaguaruna, Santa Catarina, in terms of geology, geomorphology and evolution, by analyzing surface and subsurface data, to support the coastal management in the region. The study was based on aerial photographs interpretation and geophysical analysis of GPR data. Four sedimentary deposits were identified on the surface of the coastal barrier: Eolic Deposit, Beach-Marine Deposit, Beach-Lagoonal Deposit and Paludal Deposit. Geomorphologicaly, these deposits occur as sand dunes, strandplain and wetlands, respectively. Furthermore, precipitation ridges and paleochannels are also found in the morphology of the barrier. Regarding the subsurface information, the main observation is the influence of the Urussanga River in the shallow marine and beach environment during the barrier evolution. The presence of paleochannels in subsurface along with other surface information allowed the characterization of the evolutionary behavior of the barrier as regressive. The GPR sections enable to identify the paleochannels due to the presence of concave erosive surface with high amplitude and lateral continuity. Above these surface occurs paleochannels filling in different phases. These geological and geomorphological information have important implications for the planning and territorial management.
\end{abstract}

Keywords: Holocene Barrier, Paleochannel, Ground Penetrating Radar, GIS. 


\section{Introdução}

As barreiras costeiras representam 15\% do total de linha de costa do mundo (Otvos, 2012). A origem do termo barreira costeira está relacionada ao fato de representarem uma barreira física entre o oceano e o continente. Nesse sentido, tem-se a definição de barreira costeira como uma feição arenosa alongada, emersa, que protege um corpo aquoso, correspondente à laguna, estuário ou baía, da ação direta das ondas oceânicas (Fisher \& McGowen, 1969; Boyd et al., 1992; Morton, 1994).

Entretanto, por nem sempre existir um corpo aquoso em sua retaguarda, definições mais recentes que abordam a morfologia, e não mais a função das barreiras, tem sido utilizada. Nessa abordagem, Dillenburg \& Hesp (2009) definem barreira costeira como uma estrutura paralela à linha de costa formada por acumulação de areia, cascalho, conchas e quantidades pequenas de matéria orgânica, decorrente da ação de ondas, marés e ventos.

Segundo Dillenburg \& Hesp (2009), esta feição morfológica é o elemento deposicional de maior importância de costas dominadas por ondas e de baixo gradiente, ocorrendo especialmente em costas de margens continentais passivas (trailing edge coasts), onde as topografias costeiras são mais suaves e os sedimentos são mais abundantes. Davis \& Hayes (1984) afirmam que nestas costas o transporte sedimentar através da ação de ondas predomina sob a forçante de maré, sendo normalmente associada aos ambientes de micromaré.

As barreiras costeiras são parte integrante da formação e evolução das planícies costeiras do sul do Brasil. São formadas e evoluem pela ação e processos associados às variações do nível do mar, energia de ondas, declividade da plataforma, amplitude das marés, balanço de sedimentos, geometria da costa e da topografia antecedente (Curray, 1964; Davis \& Hayes, 1984; Lessa et al., 2000; Dillenburg \& Hesp, 2009).

Segundo Caron (2014), o estudo da evolução das planícies costeiras brasileiras durante o Holoceno teve seu início na década de 60 . No entanto, foi com a proposta de Villwock et al. (1986) de aplicar o modelo de sistemas deposicionais do tipo Laguna-Barreira, com caráter cronoestratigráfico, que houve o crescimento de estudos nesse sentido. $\mathrm{Na}$ Planície Costeira do Rio Grande do Sul destacam-se diversos trabalhos, como Tomazelli (1990), Dillenburg (1994), Villwock \& Tomazelli (1995), Dillenburg et al. (2000, 2004, 2006, 2009, 2013, 2017), Clerot (2004), Travessas et al. (2005), Martinho et al. (2008), Barboza et al. (2009, 2011a, 2011b, 2013), Rosa et al. (2011, 2017), Rosa (2012), Lima et al. (2013) e Caron (2014), cada um com enfoques e áreas distintas, contribuindo para o entendimento da evolução desta região.

Em Santa Catarina os trabalhos sobre evolução de planícies costeiras são mais recentes e ainda há poucos trabalhos. Destacam-se os trabalhos de Barboza et al. (2009, 2014a), Fornari (2010), Tanaka (2010), Biancini da Silva $(2011,2016)$ Biancini da Silva et al. (2014), Dillenburg et al. (2011, 2014), Hein et al. (2013), Dillenburg \& Barboza (2014), e Leal et al. (2016).

0 presente estudo tem como objetivo caracterizar, com base em dados de superfície e subsuperfície, a evolução da barreira costeira holocênica do setor Sul do município de Jaguaruna, situado no litoral de Santa Catarina.

\section{2 Área, material e método}

\subsection{Localização e aspectos gerais da área de estudo}

A costa de Jaguaruna está situada ao sul do Cabo de Santa Marta e compreende aproximadamente $38 \mathrm{~km}$ de costa, com orientação preferencial de NE-SW, exposta a todas as direções de ondas e ventos.

Ao longo de sua extensão, sangradouros desembocam no oceano. Esta característica é similar ao litoral médio e norte do Rio Grande do Sul, em que Calliari et al. (2005) destacam a importância desses sangradouros na drenagem da zona costeira e remobilização de sedimentos das dunas e face de praia. Os cursos d'água de maior influência são os que limitam o município, ao norte o canal do Camacho, e ao sul a desembocadura do Rio Urussanga.

A setorização da orla do município de Jaguaruna é segmentada em setor Norte, Central e Sul, a partir dos estados morfodinâmicos da praia. A área de estudo abrange a barreira holocênica do Setor Sul, o qual envolve o Balneário Torneiro (Fig. 1).

Os aspectos geológicos e geomorfológicos da área de estudo e suas adjacências foram estudados e caracterizados por alguns autores, dentre eles Giannini (1993), Giannini \& Suguio (1994), Martinho et al. (2006), Vieira et al. (2009), Fornari (2010), Tanaka (2010), Horn Filho et al. (2010, 2014), Barboza et al. (2014b), Dillenburg \& Barboza (2014) e Martins et al. (2014).

Em grande parte da planície costeira catarinense há somente o registro dos mais recentes sistemas Laguna-Barreira: pleistocênico (Barreira III) e holocênico (Barreira IV). Para a região de Jaguaruna, Vieira et al. (2009) propuseram um 
modelo paleogeográfico sintetizado em quatro estágio evolutivos com base nas variações do nível do mar, desde a regressão do Pleistoceno inferior (>120 ka AP) até o início da regressão do máximo holocênico ( $\sim 5,4$ ka AP). Esta proposta é similar ao modelo evolutivo Laguna-Barreira proposto por Villwock et al. (1986) e Tomazelli \& Villwock (2000) para o Rio Grande do Sul, também utilizado em alguns trabalhos para o litoral sul catarinense, por pertencer à Bacia de Pelotas.

O clima na região é do tipo Cfa, na classificação de Koeppen (1948 apud Alvares et al., 2014), subtropical úmido mesotérmico, sem a presença de estação de seca e com verões quentes (Alvares et al., 2014). 0 Anticiclone Tropical do Atlântico Sul predomina nos meses de primavera-verão, o que ocasiona ventos de leste a nordeste. No outono-inverno a área é atingida pelo Anticiclone Móvel Polar com predominância de ventos do quadrante sul (Orselli, 1986).

As características das ondas refletem o regime de vento sobre o Atlântico Sul. Portanto, durante as estações primavera e verão, a direção predominante das ondas é do quadrante leste. Já nos meses de outono e inverno a passagem dos sistemas frontais produz ventos e ondas do quadrante sul. A altura significativa das ondas é de 1,15 m (de leste), e $2 \mathrm{~m}$ (de sul), com períodos na faixa de $8 \mathrm{e}$ $12 \mathrm{~s}$, respectivamente (Araújo et al., 2003). A costa tem regime de micro-maré, semi-diurna e com uma gama média de $0,5 \mathrm{~m}$. Relacionada com as marés meteorológicas, a amplitude pode ser mais expressiva na região e alcançar 1 m (Giannini, 1993).

A deriva litorânea na região sul de Santa Catarina é controlada pelas ondas do quadrante sul que, apesar de menos frequentes, são mais intensas. Entretanto, é relevante salientar que Siegle \& Asp (2007) concluíram que entre a desembocadura do Rio Araranguá e o Cabo de Santa Marta, num período anual, a deriva possui um caráter bidirecional, e apresenta uma clara diminuição no potencial de transporte, comparado a outros setores. Segundo os mesmos autores, a deriva no setor entre o Rio Araranguá e o Cabo predomina para norte nos meses de outono, inverno e verão, e para sul na primavera.

Esse comportamento é decorrente da mudança na orientação da linha de costa nesse setor.

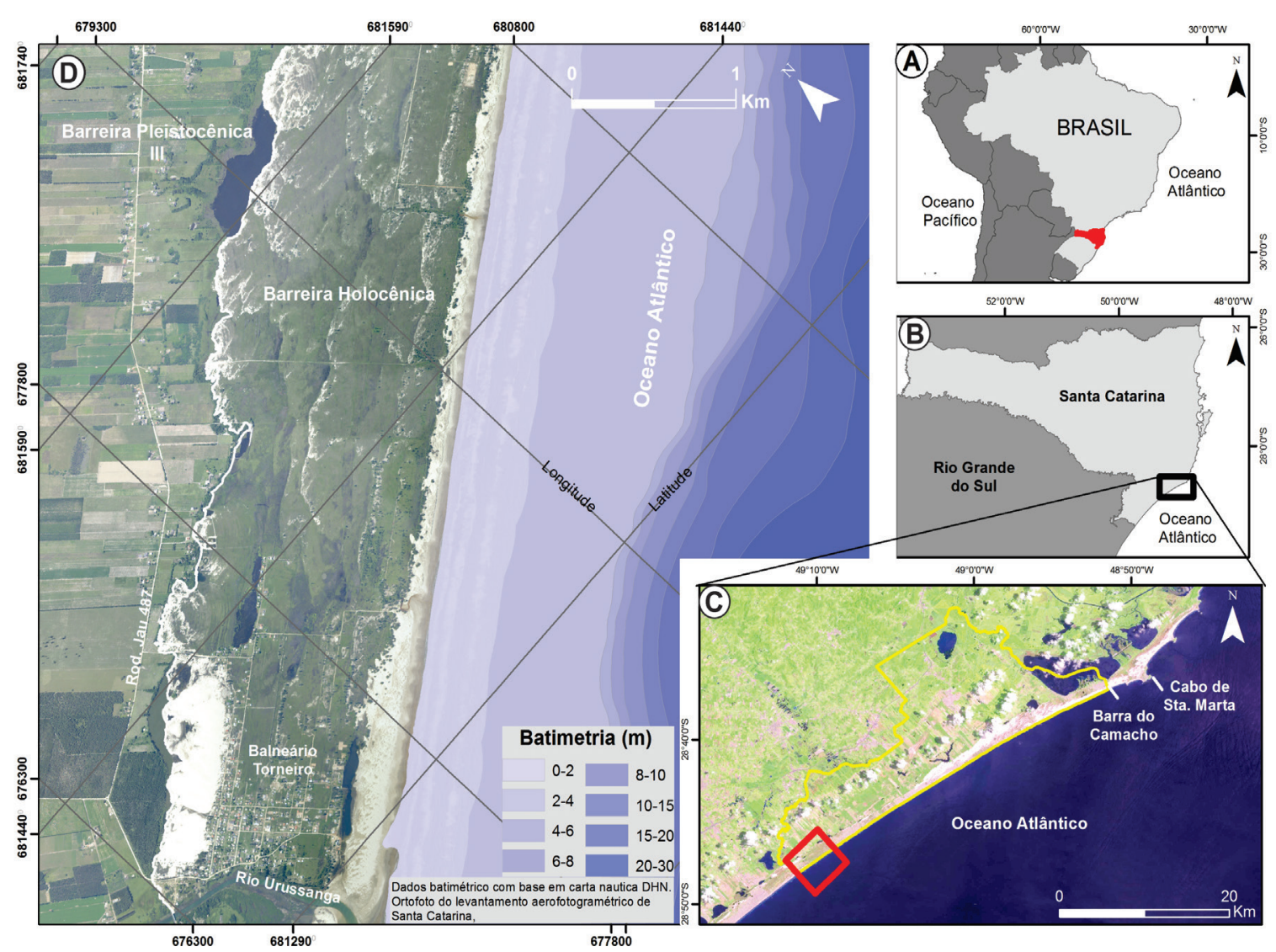

Figura 1. Localização da área de estudo. A) Localização no Brasil; B) Localização no Estado de Santa Catarina; C) Delimitação do Município de Jaguaruna (em amarelo) e setor sul de Jaguaruna (em vermelho), com localização da barra do Camacho e do Cabo de Santa Marta; D) Área de estudo com delimitação da barreira costeira holocênica, e localização do Balneário Torneiro e do Rio Urussanga.

Figure 1. Study area location. A) Location in Brazil; B)Location in Santa Catarina State; C) Delimitation of Jaguaruna's Municipality (yellow) and the southern sector of Jaguaruna (red), with location of Barra do Camacho and Santa Marta Cape; D) Study area with delineation of Holocene coastal barrier and location of Balneário Torneiro and Urussanga River. 
As ondas de sul incidem na costa de maneira mais perpendicular $\left(\sim 90^{\circ}\right)$, diminuindo a efetividade da deriva longshore, predominando o transporte onshore, e um equilíbrio no transporte longitudinal anual (Siegle \& Asp, 2007).

\subsection{Materiais e métodos}

\subsubsection{Levantamento geológico e geomorfológico de superfície}

O levantamento geológico e geomorfológico de superfície foi elaborado em quatro etapas: revisão bibliográfica, fotointerpretação, vistorias in loco e confecção do mapa temático final.

Na revisão bibliográfica, documentos cartográficos foram obtidos em meio analógico e digital de acordo com a disponibilidade. Esta etapa consistiu em obter o maior número de fontes e materiais em diferentes escalas espaciais e temporais da área de estudo. Dentre os materiais obtidos ressaltam-se as aerofotos de 1938, 1957 e 1978, e as ortofotos de 2010, todas cedidas pela Secretaria de Desenvolvimento Sustentável (SDS) de Santa Catarina.

0 trabalho de fotointerpretação foi realizado em ambiente de Sistema de Informação Geográfica (SIG), através do software ArcGIS 10.2.2. Compreendeu primeiramente no georreferenciamento das aerofotos, utilizando pontos de controle das ortofotos de 2010. Posteriormente, realizou-se a identificação das unidades geológicas e geomorfológicas através da interpretação das fotografias aéreas, considerando os seguintes fatores: textura, tonalidade, estruturas, formas topográficas características e posição geográfica em relação à linha de costa atual. Além das aerofotos e ortofotos, imagens de satélites obtidas no software Google ${ }^{T M}$ Earth Pro serviram de apoio à interpretação.

Para confirmar as informações obtidas na fotointepretação foram realizados os trabalhos de campo, com objetivo principal de descrever as unidades mapeadas ao longo da área de estudo e registrá-las, para corroborar com as análises da fotointerpretação.

Por fim, os dados obtidos ao longo do processo foram integrados e analisados em ambiente SIG e, através de técnicas de geoprocessamento, foi elaborado o mapa temático geológico/geomorfológico.

\subsubsection{Radar de Penetração de Solo (GPR)}

O GPR é um método geofísico que emprega ondas eletromagnéticas de alta frequência (de 40 a $400 \mathrm{MHz}$ em estudos geológicos costeiros) para localizar estruturas e feições geológicas rasas em subsuperfície. Neste estudo, o GPR foi dividido em três etapas: aquisição, processamento e interpretação. Na aquisição estão envolvidas questões relacionadas com o método de levantamento e com a seleção dos equipamentos. Principalmente no que tange a aquisição de dados, este trabalho seguiu a sistemática proposta por Barboza et al. (2014c).

0 equipamento utilizado na aquisição dos dados foi o GPR da empresa GSSI ${ }^{\mathrm{TM}}$ (Geophysical Survey Systems, Inc.) modelo SIR-3000 e uma antena de contato com frequência central de $200 \mathrm{MHz}$. 0 arranjo utilizado foi Common Offset monoestático que consiste no deslocamento simultâneo da antena receptora e transmissora, mantendo uma distância fixa entre elas de $0,5 \mathrm{~m}$. A antena foi acoplada a um veículo que a transportou orientadas perpendicularmente ao sentido de deslocamento, com velocidade média de $20 \mathrm{~km} / \mathrm{h}$.

Desta forma, obtiveram-se seções contínuas de imageamento sob a linha de deslocamento da antena. A profundidade das janelas atingiu de 200 a $400 \mathrm{~ns}$, as quais correspondem às profundidades aproximadas entre 10 e $20 \mathrm{~m}$. Cada traço de seção representa o empilhamento de 32 leituras (stacking), tendo sido aplicado um ganho do tipo AGC (Automatic Gain Control), com a finalidade de equalizar a amplitude dos traços. A constante dielétrica utilizada durante a aquisição foi a de valor 10 , que representa uma velocidade de $0,09 \mathrm{~m} / \mathrm{ns}$, geralmente relacionada a depósitos arenosos (Davis \& Annan, 1989).

As correções dos dados altimétricos foram feitas através do acoplamento do sistema de GPR a um sistema de posicionamento GNSS Trimble PROXRS no modo cinemático, gerando um arquivo de posicionamento espacial e altimétrico pós processado para as devidas correções topográficas das seções.

A segunda etapa do trabalho consistiu no processamento das seções. De acordo com Rosa (2012), o que define os métodos de processamento a serem utilizados são os objetivos e os tipos de feições que se deseja identificar. Sendo assim, é importante atentar para o fato que o objetivo do processamento é eliminar/minimizar os dados considerados com ruídos, e ressaltar os que podem representar alguma informação.

Os dados foram processados nos programas RADAN $^{T M}$ e PRISM ${ }^{\circledR}$ com a aplicação de filtros limitantes de frequência, remoção de ruídos contínuos (background removal), ganho de sinal, correção topográfica e correções de tempo em profundida- 
de. As interpretações das radarfácies seguiram o método da sismoestratigrafia adaptado por Neal (2004), baseado nas terminações (onlap, toplap, downlap e truncamentos) e no padrão e geometria dos refletores (Mitchum Jr. et al., 1977). Radarfácies referem-se às diferenças visíveis no padrão de reflexão de uma seção de GPR, ocasionadas por feições com características estruturais e texturais em subsuperfície (Van Overmeeren, 1998).

\section{Resultados e discussões}

A análise geológica e geomorfológica de superfície foi o resultado das informações obtidas pelas técnicas de geoprocessamento (SIG e Sensoriamento Remoto); as informações referentes à arquitetura deposicional foram decorrentes das interpretações dos dados geofísicos obtidos com o GPR.

\subsection{Análise geológica e geomorfológica de superfície}

Com base na interpretação de fotografias aéreas e de imagens de satélite, e nas observações realizadas em campo, foi elaborado o mapa geológico-geomorfógico da área de estudo na escala 1:18.000 (Fig. 2).

A caracterização e nomenclatura utilizada para os depósitos sedimentares seguiram os pa- drões de Horn Filho et al. (2014), o qual classifica os depósitos da barreira holocênica em depósitos litorâneos ou transicionais. Na área de estudo foram identificados quatro depósitos distintos: Depósito Lagunar Praial, Depósito Paludial, Depósito Eólico (Estabilizado, Ativo, Frontal) e Depósito Marinho Praial.

Devido à presença de cordões litorâneos próximo às lagoas a área foi caracterizada como Depósitos Lagunar Praial, pois essas feições são típicas de ambiente marinho costeiro. Esses depósitos se expressam como feição geomorfológica, denominada cordão litorâneo (beach ridge) ou crista litorânea, e consiste em um depósito praial (cordão/crista de praia) de orientação paralela à linha de costa, de natureza relíquia, preservados por vegetação e separados uns dos outros por depressões (cavas). Ocorrem tanto em costas oceânicas quanto em corpos aquosos confinados ou semiconfinados (Woods \& Leahy, 1983). O segundo caso ocorre na área de estudo, onde aproximadamente 15 cordões estão em evidência na morfologia atual da barreira.

Diversos estudos discorrem sobre os processos dominantes para gêneses dos cordões, mas de uma maneira geral quatro processos são dominantes: (i) ondas de tempestade; (ii) ondas de tempo bom; (iii) variação do nível de base; e (iv) processos eólicos, os quais muitas vezes agem em combi-

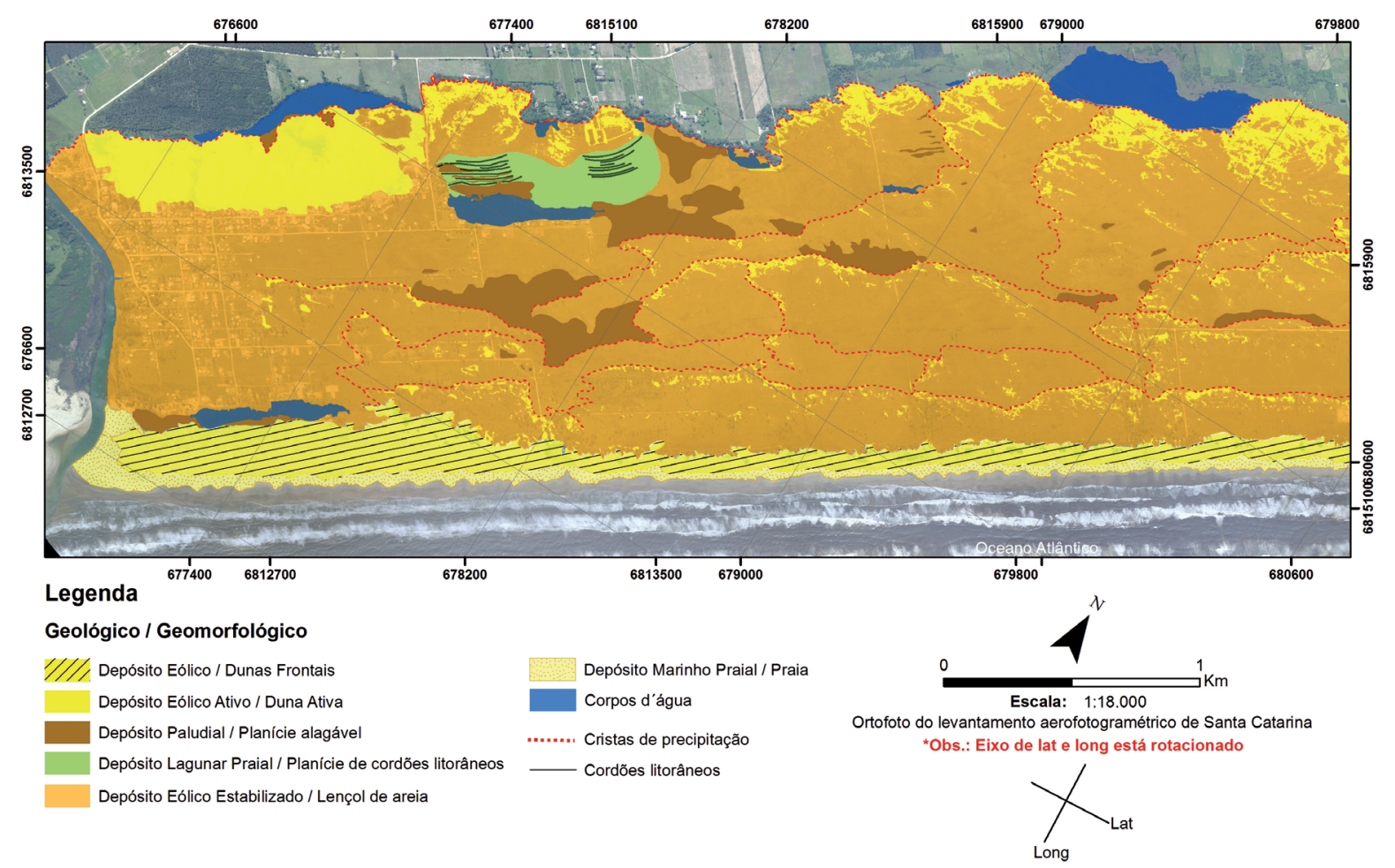

Figura 2. Mapa geológico-geomormofógico da barreira costeira holocênica do setor sul de Jaguaruna.

Figure 2. Geological and geomorphological map of Holocene coastal barrier of the southern sector of Jaguaruna. 
nação (e.g. Tanner, 1996; Otvos, 2012; Hesp, 2006; Tamura, 2012; Bitencourt, 2015).

Quanto à classificação, Tanner (1996) propôs uma síntese com quatro categorias, de acordo com os processos envolvidos na gênese dos depósitos, nos quais foram classificadas em: (i) Espraiamento; (ii) Setting lag; (iii) Eólicos; e (iv) nível d'água elevado por tempestade.

A origem dos cordões na área de estudo está relacionada aos processos envolvidos na colmatação da lagoa. Os ventos do quadrante nordeste transportavam sedimentos dos campos de dunas, que ao mesmo tempo em que aportava sedimento para formação dos cordões, diminuía o nível de base da lagoa como consequência da colmatação. Esses ventos também produziam, e ainda produzem ondas no interior da lagoa. Sendo assim, o processo de espraiamento também foi componente na formação dos cordões. Aliado a esses processos ainda ocorreu à diminuição do nível de base resultado da regressão marinha ocorrida no Holoceno. Esta regressão teve início após o máximo transgressivo holocênico, ocorrido há 5,4 ka AP (Angulo et al., 2006).

Assim, definir uma classificação específica para os cordões em questão não é adequado, pois sua gênese é resultado da combinação de diversos processos. No entanto, a identificação dos cordões, tanto em lagoas como em praias, é de suma importância paleoambiental e paleogeográfica pela capacidade de ser utilizados como proxies, neste caso, de oscilação de nível de base e variações climáticas.

Os Depósitos Paludiais são constituídos de sedimentos lamosos orgânicos, argilas plásticas e fragmentos vegetais, típicos de pântanos, alagados e regiões semi-submersas de água doce ou salobra, resultado do nível do freático alto associado à alta pluviosidade formando banhados. Os sedimentos são geralmente muito pobremente selecionados, constituem áreas complexas periodicamente inundáveis, relacionadas com estuários de rios e lagoas associadas, com desembocadura no oceano, sujeitos à influência das águas marinhas por ocasião das marés altas (Horn Filho et al., 2014)

Esses depósitos estão bem presentes na área de estudo e provavelmente estão associados ao retrabalhamento do Rio Urussanga sobre a planície ao longo da progradação da barreira. Ao analisar a evolução espaço-temporal através das aerofotos, observa-se que esses ambientes ficaram em evidências após a estabilização dos campos de dunas.

Os Depósitos Eólicos têm como agente dominante o vento, principal responsável pela for- ma das feições geomorfológicas do tipo duna. Os sedimentos constituintes desse depósito são geralmente compostos de areias quartzosas bem selecionadas, com tamanho de grão predominantemente areia fina. 0 sistema eólico está representado por duna frontal (instável e estável), campo de dunas interior e lençóis de areia transgressivos (transgressive dune sheets).

As dunas frontais ocorrem com duas morfologias distintas na área de estudo. Hesp (2000) discorre sobre os tipos de dunas frontais, classificando-os em cinco tipos, levando em consideração a estabilidade da duna, conforme o estágio da vegetação e o nível de erosão da duna frontal (Fig. 3).

Da desembocadura do Rio Urussanga, até cerca de 1,4 km ao norte, existe a formação de dunas frontais instáveis (Fig. 4A). Estas dunas se prolongam da interface entre o sistema praial e eólico até $250 \mathrm{~m}$ de continente adentro, na forma de pequenos cômoros com vegetação incipiente, a qual, segundo a proposta de Hesp (2000), correspondem ao tipo 5.

Essas dunas vão diminuindo sua extensão em direção ao norte da desembocadura do Rio Urussanga e, a partir de $1,4 \mathrm{~km}$, mudam sua característica, passando a apresentar uma morfologia típica de duna frontal estável, com cordão frontal bem definido com uma altura aproximada de 2,5 m (Fig. 4B). Essa morfologia de duna frontal se enquadra no tipo 2 da classificação de Hesp (2000).

A diferença morfológica que ocorre nas dunas frontais ao longo da costa está relacionada à influência do suprimento sedimentar da descarga do Rio Urussanga e à dinâmica da desembocadura sobre os depósitos praiais e eólicos adjacentes.

A deriva litorânea na região é bidirecional (Siegle \& Asp, 2007). Essa variação influencia no transporte e deposição dos sedimentos no sistema praial ao longo da costa. Quando a deriva predomina para nordeste, a desembocadura do rio acompanha, e os sedimentos trazidos pelo rio são transportados e depositados ao norte do estuário, ocasionando um acúmulo de sedimento no sistema praial; no momento que a deriva predomina para sul, a desembocadura também migra, transportando e depositando os sedimentos ao sul do estuário. Quando essa inversão ocorre, provoca um déficit sedimentar nas adjacências ao norte, originando um período de erosão nesse setor.

Através da análise da linha de costa entre os anos de 1978 e 2010 é possível observar que ocorre uma diminuição na taxa de erosão conforme se distancia da desembocadura (Fig. 5A). Além disso, a dinâmica da desembocadura retrabalha os depó- 


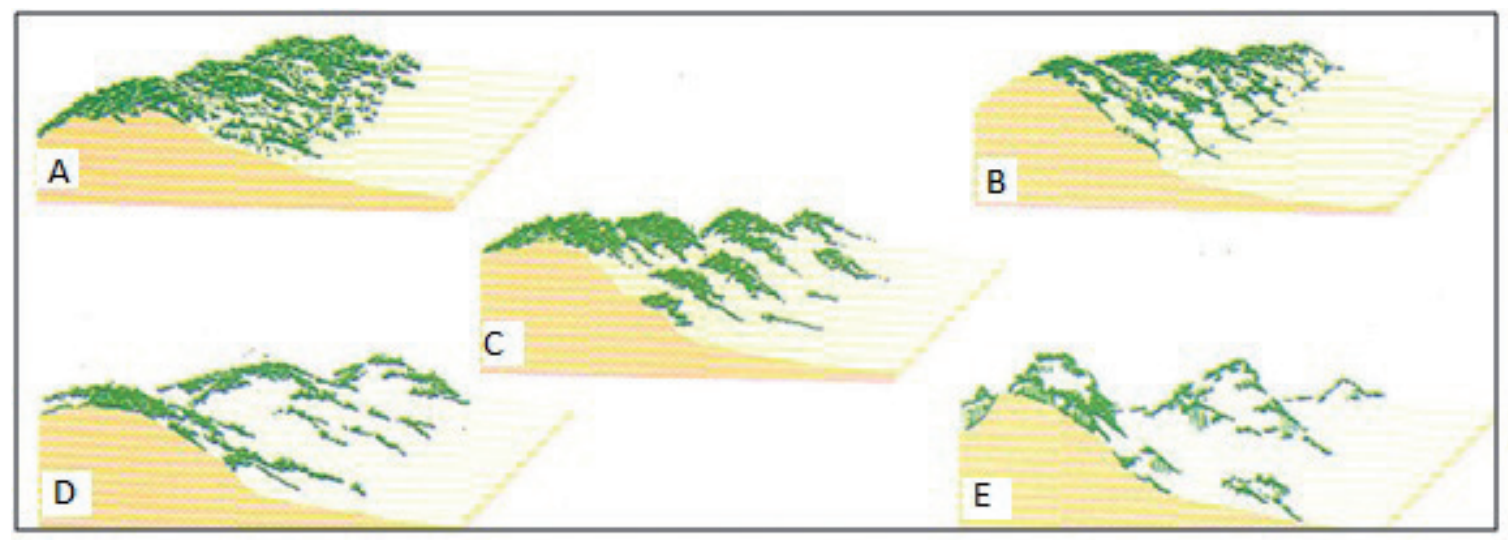

Figura 3. Tipos de dunas frontais variando de estável e vegetada (A) a altamente erosiva (E) (adaptado de Hesp, 2000). A) Tipo 1; B) Tipo 2; C) Tipo 3; D) Tipo 4; E) Tipo 5.

Figure 3. Foredune types ranging stable and vegetated (A) to highly erosive (E) (adapted from Hesp, 2000). A) Type 1; B) Type 2; C) Type 3; D) Type 4; E) Type 5.

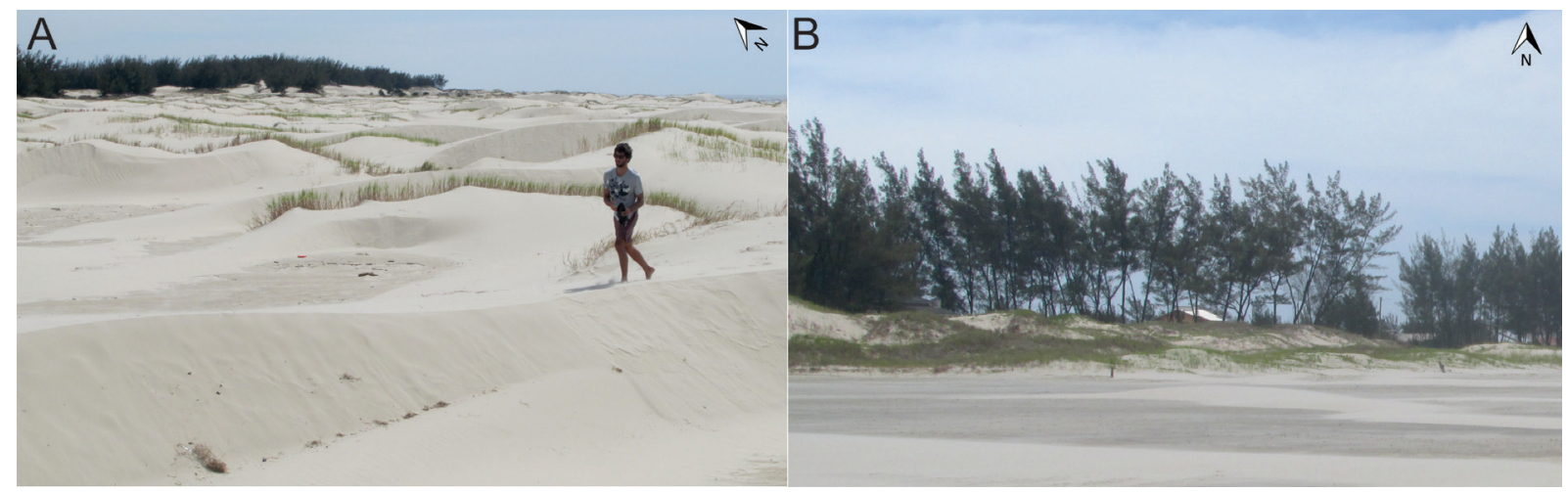

Figura 4. Características morfológicas das dunas frontais. A) Duna frontal instável altamente erosiva com vegetação incipiente; B) Duna frontal estável com cordão frontal bem definido localizada a 1,4 km ao norte da desembocadura do Rio Urussanga. Figure 4. Morphological characteristics of the frontal dunes. A) Highly erosive unstable frontal dune with incipient vegetation; B) Stable frontal dune with well-defined foredune ridge located $1.4 \mathrm{~km}$ north of the Urussanga River mouth.

sitos praiais e eólicos adjacentes ao rio, tanto ao norte quanto ao sul do estuário, tornando-os mais instáveis e dificultando a estabilização das dunas frontais. Esse processo fica evidente ao observar que as dunas frontais se apresentam mais estabilizadas quanto mais distantes da desembocadura.

No limite noroeste da área de estudo há um extenso campo de dunas móvel. Apesar de não apresentar indícios de estabilização, não existe mais aporte de sedimento para mantê-lo, logo, a tendência é que ocorra o mesmo processo do restante da barreira, e tornando-o um lençol de areia estabilizado.

Os lençóis de areia recobrem grande parte da barreira de forma vegetada, com pequenas áreas esparsas ainda sem vegetação. Caracterizados por Tomazelli (1994), os lençóis correspondem a acumulações arenosas promovidas pelo vento sem que ocorra o desenvolvimento de morfologia de duna.

Uma feição bastante marcante destes lençóis são as cristas de precipitação (precipitation ridges). São cristas de areia longas e estreitas, for- madas pela saltação dos sedimentos depositando sobre a vegetação nas margens externas do campo de dunas (Hesp \& Tom, 1990; Hesp, 2004). Observam-se aproximadamente quatro fases/pulsos limitados por essas cristas (Fig. 5A). Segundo Hesp (2000), o entendimento dos mecanismos ou fatores responsáveis pela inicialização dessas fases/ pulsos de desenvolvimento de dunas ainda são extremamente limitados. Entretanto, Hesp et al. (2007) discorrem teorias sobre a formação dessas feições, a qual associa essas fases a três hipóteses: mudanças do nível de base, mudanças climatológicas e alterações no aporte de sedimento.

Com base na análise de fotografias pretéritas foi possível identificar a migração das dunas sentido continente (direção sudoeste) mesmo após a estabilização dessa cobertura eólica da barreira (Fig. 5A). Isto ocorre, pois mesmo que não haja mais aporte de sedimento para o campo de dunas devido à estabilização, ainda ocorre disponibilidade de sedimentos no próprio campo, o qual continua migrando pela ação dos ventos de nordeste.

A análise também permitiu visualizar que em 
1938 a barreira em questão apresentava um extenso e ativo campo de dunas transgressivo. Nas imagens de 1976 é evidente o início do aumento da cobertura vegetal e consequente estabilização desse campo, resultando na diminuição das dunas móveis.

Miot da Silva et al. (2013) discorrem sobre essas mudanças geomorfológicas ocorridas nos campos de dunas no sul do Brasil, e atribuem como principal fator as variações climáticas regionais decorrentes da Oscilação Decadal do Pacífico e dos eventos de El Niño. De acordo com os autores, após a segunda metade do século XX houve um aumento da temperatura e das chuvas, e também uma diminuição na velocidade dos ventos, contribuindo para o estabelecimento da vegetação e estabilização dos campos de dunas. Com maior disponibilidade de água, lençol freático mais alto, e menor deriva dos sedimentos eólicos, plantas colonizaram mais facilmente os campos de dunas ao longo da costa, estabilizando-os total ou parcialmente no final dos anos 70 .
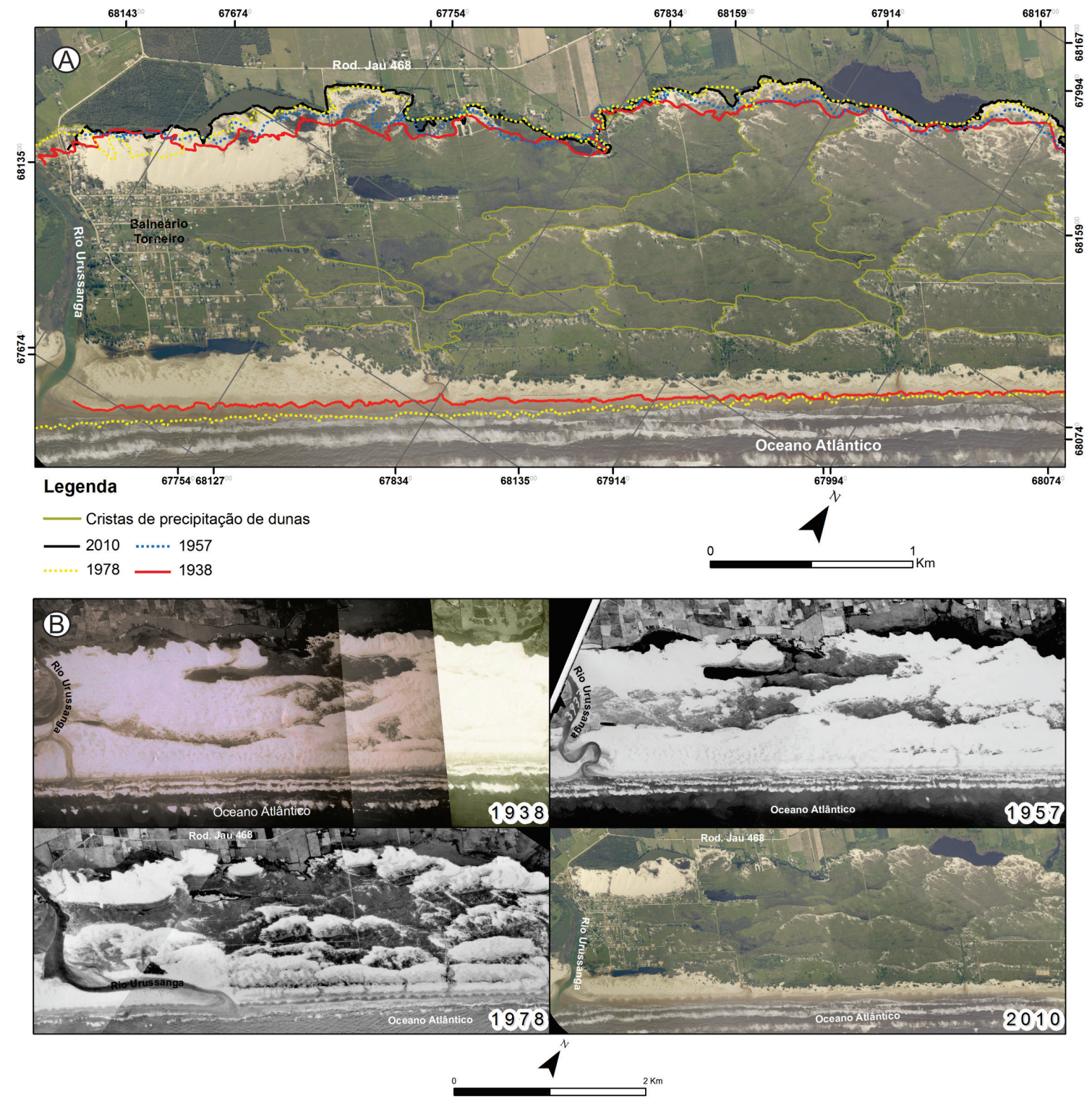

Figura 5. Análise evolutiva multitemporal do campo de dunas e da linha de costa. A) Análise multitemporal da migração das dunas e identificação das cristas de precipitação presentes na barreira e análise multitemporal do comportamento da linha de costa, indicando erosão nos últimos 30 anos nas adjacências da desembocadura, com tendência a estabilidade em direção ao norte; B) Conjunto de fotografias aéreas evidenciando a estabilização e consequente diminuição do campo de dunas móveis entre 1938 e 2010.

Figure 5. Multitemporal evolutionary analysis of the dune field and the coastline. A) Multi temporal analysis of the migration of dunes and identification of precipitation ridges present in barrier and multi temporal analysis of the shoreline behavior, indicating erosion over the past 30 years in the adjacencies of the mouth, with a tendency to stability in the north; B) Aerial photo set showing the stabilization and subsequent reduction of the mobile dune field between 1938 and 2010. 
Os corpos d'água alongados com direção NE-SW presentes na barreira holocênica representam paleocanais do Rio Urussanga que foram abandonados, e atualmente apresentam características e processos lagunares. É importante salientar que os corpos d'água de mesmas características situados no limite entre as barreiras holocênica e a pleistocênica, mesmo fora do escopo deste trabalho, provavelmente não são paleocanais, e sim lagoas ou lagunas em processo de colmatação pelo avanço do sistema eólico sobre elas, como encontrados em outras áreas ao norte (Balneário Esplanada) e ao sul (Balneário Rincão). Este processo de colmatação, influenciado por sistemas eólicos, também ocorre no litoral norte do Rio Grande do Sul. Ao sul de Tramandaí, a migração das dunas eólicas é o principal processo responsável pela evolução dos corpos lagunares (Tomazelli, 1993; Lima et al., 2013; Barboza \& Rosa, 2014; Caron, 2014).

Os Depósitos Marinho Praiais correspondem a parte dos sedimentos da barreira arenosa do pós-praia e da antepraia, representado geomorfologicamente pelas praias atuais. É um ambiente dinâmico, modificado a todo instante pelos processos marinhos costeiros, como ondas, marés, correntes litorâneas e ventos. Foi delimitado ao oeste pelas dunas frontais e a leste pelo nível de maré baixa. $\mathrm{Na}$ área de estudo, o pós-praia tem uma extensão que varia entre 25 e $60 \mathrm{~m}$.

\subsection{Arquitetura Deposicional}

Após a caracterização geomorfológica e geológica de superfície, perfis geofísicos foram realizados, sendo adquiridos cerca de $18 \mathrm{~km}$ de dados, divididos em 18 perfis. Destes, 10 foram de forma transversal (dip) à barreira, e oito perfis paralelos (strike) à linha de costa. A penetração do sinal variou entre 07 e $12 \mathrm{~m}$, e diferentes radarfácies foram identificadas, correspondentes a depósitos quaternários, provavelmente de idades holocênicas. Dentre os 18 perfis, duas seções transversais NW-SE foram selecionadas para ilustrar a arquitetura deposicional da barreira.

Primeiramente, para corroborar com as interpretações de superfície na identificação do comportamento evolutivo da barreira, buscou-se analisar o padrão de empilhamento. Uma barreira progradacional (regressiva) ocorre quando a taxa de aporte sedimentar supera a taxa do espaço de acomodação da bacia. Devido a isso, os sistemas deposicionais migram no sentido do depocentro da Bacia, ou seja, predominam os processos deposicionais no pós-praia, com o aumento da barreira e a consequente regressão da linha de costa (Roy et al., 1994).

Em barreiras com este comportamento o padrão de empilhamento esperado é representado pela sobreposição de três fácies principais: fácies marinho raso, fácies praial e fácies eólica, respectivamente (e.g. Dillenburg et al., 2011; Barboza et al., 2013; Biancini da Silva et al., 2014).

Entretanto, na área de estudo observou-se que a dinâmica do Rio Urussanga retrabalhou a barreira durante a sua progradação, e impossibilitou a preservação deste tipo de padrão. Desta forma, a arquitetura deposicional predominante na conformação interna da barreira segue o padrão da seção 1 (Fig. 6A), onde foram interpretadas superfícies erosivas, feições de subsuperfície (paleocanais) e três radarfácies (RF-1, RF-2, RF-3).

Superfície erosiva: As superfícies erosivas foram reconhecidas e caracterizadas por refletores de alto contraste e lateralmente contínuos, com presença de truncamentos no contato com a radarfácies de plano inferior. Elas estão presentes regularmente em duas profundidades diferentes: 2,5 e 5 m (Fig. 6A).

Feição de Subsuperfície (Paleocanal): Os paleocanais são representados por superfícies erosivas de forma levemente côncava que truncam diferentes radarfácies e são compostos por radarfácies de preenchimento (Fig. 6B). As superfícies erosivas representam a base dos paleocanais e estão relacionadas com a máxima incisão alcançada pela dinâmica do rio. A caracterização destes paleocanais também ocorre pela identificação da incidência de terminações onlap e toplap na face côncava, e truncamentos na face convexa (Fig. 7A e 7B).

Dificilmente a morfologia do paleocanal em subsuperfície é representada por uma superfície erosiva de forma côncava bem definida. Em geral, são superfícies interrompidas e em alguns casos apresentam apenas uma margem (Fig. 6A). De acordo com Biancini da Silva (2016), autor que também encontrou essas feições em seu trabalho, este comportamento indica que os paleocanais migraram por movimentos laterais e/ou abandonaram um antigo curso para iniciar um novo percurso sobre a barreira. Estes processos podem ser resultado de diversos fatores, como uma avulsão do canal devido a uma cheia do rio, bloqueio do canal devido à progradação da barreira e até mesmo como consequência das variações no NRM.

Marinho Raso (upper Shoreface) (RF-1): A RF-1 está entre as profundidades de 4,5 e $10 \mathrm{~m}$, seus refletores são descontínuos, subparalelos e 
com alta amplitude, correspondente a um ambiente marinho raso (upper shoreface), formados e preservados devido ao caráter progradacional da barreira. Padrões similares a este foram observados em perfis de GPR por Barboza et al. (2009, 2010, 2011b, 2013) e Dillenburg et al. (2011). Biancini da Silva (2016), em uma região mais ao sul da área de estudo, também identificou essa radarfácies em profundidade semelhante.

Preenchimento de Canal (RF-2): Esta radarfácies representa o retrabalhamento do rio sobre o depósito praial e por vezes sobre marinho raso. A RF-2 alterna fases de preenchimento de canal com fases de reativação. Esse processo fica claro na figura $6 \mathrm{~A}$, onde em aproximadamente $6 \mathrm{~m}$ de profundidade se observa uma superfície erosiva, a qual representa o limite de uma incisão fluvial, ou seja, a base de um paleocanal. Acima dessa superfície ocorre um preenchimento com aproximadamente $3 \mathrm{~m}$ de espessura, e logo acima ocorre uma nova superfície erosiva, que indica uma nova incisão fluvial, representando um momento de reativação do paleocanal.

Desta maneira, observam-se dois padrões de canais distintos. 0 primeiro, em uma profundidade aproximada de $2,5 \mathrm{~m}$, representa canais mais rasos que provavelmente evidenciam reativações efêmeras do canal com menor poder de incisão, devido ao curto tempo de atuação do mesmo (Fig. 6A).

$O$ segundo padrão se estabelece em uma pro- fundidade maior, em torno de $5 \mathrm{~m}$, e representa paleocanais mais antigos e/ou momentos de mais energia e maior poder de incisão. Esse segundo padrão também é observado na seção 2 , ilustrado na figura $7 \mathrm{~A}$.

0 preenchimento dos paleocanais foi subdividido em duas radarfácies: RF-2a e RF-2b, baseado nos padrões de refletores (Fig.7B e 8A).

A RF-2a corresponde a um preenchimento por sedimento oriundo da influência eólica como resultado dos ventos nordeste (cross-onshore), que possui ação majoritária na área de estudo. Os refletores são paralelos e subparalelos, alternando alto e médio contraste, com terminações downlap na superfície erosiva no sentido do depocentro do paleocanal. A RF-2b apresenta refletores paralelos, contínuos e de baixo contraste. Esta radarfácies representa o preenchimento do paleocanal por sedimentos finos relacionados a período de baixa energia que ocorrem após seu abandono e/ou migração lateral.

Eólico (RF-3): No topo dos perfis com aproximadamente $1 \mathrm{~m}$ de espessura, refletores ondulados, contínuos, com alto contraste apresentando baixas inclinações em ambos os sentidos, representam o capeamento eólico dos lençóis de areias transgressivos. Padrões similares a estes foram descritos por Barboza et al. (2013, 2014a), Caron (2014) e Biancini da Silva (2016).

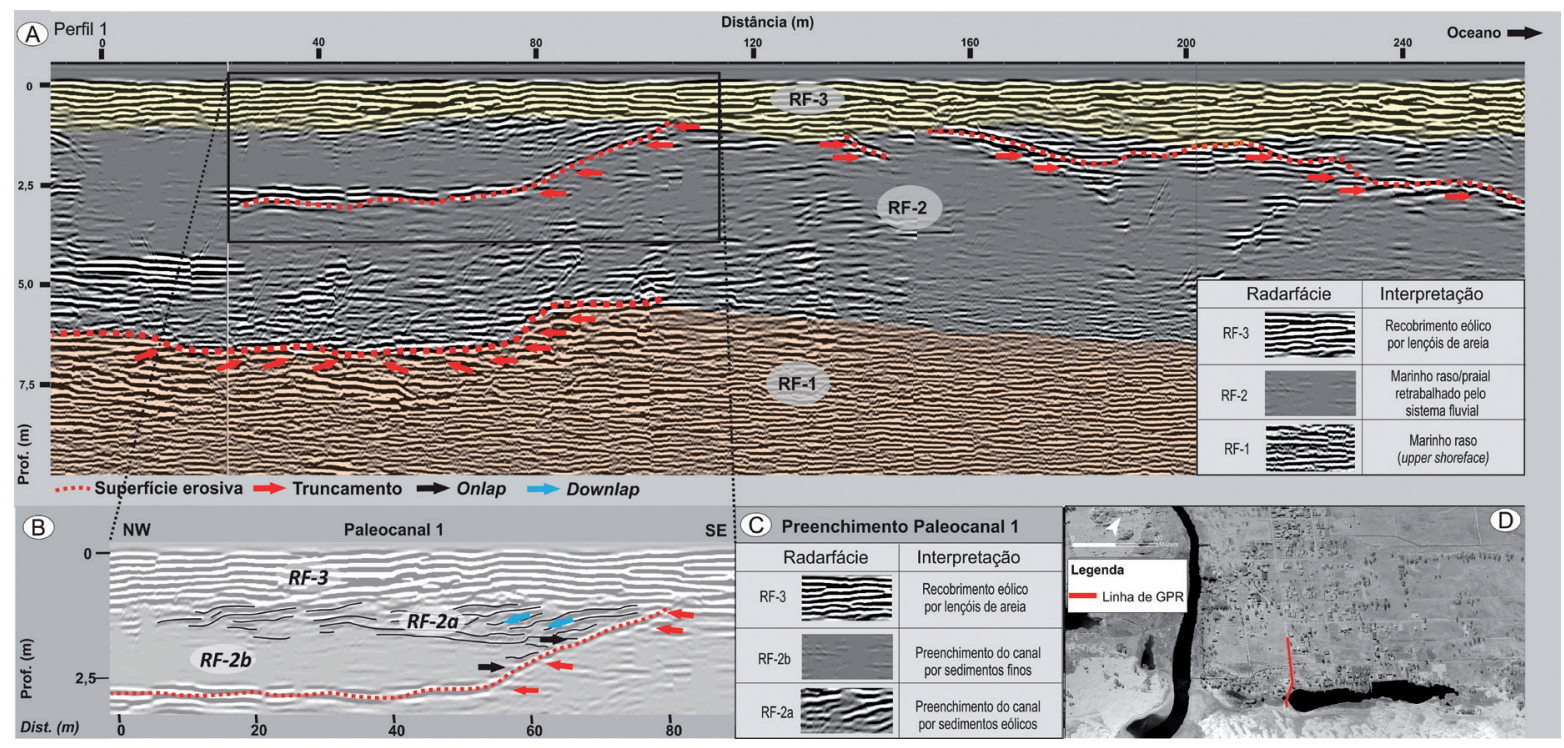

Figura 6. Seção de GPR 1 (antena de 200 MHz). A) Radarfácies identificadas: marinho raso (RF-1), marinho raso/praial retrabalhado pelo sistema fluvial do Rio Urussanga (RF-2), seguido pelo o capeamento eólico representado por lençóis de areia (RF-3); B) Detalhe do paleocanal com as radarfácies de preenchimento; C) Interpretação das radarfácies de preenchimento; D) Localização da seção realizada perpendicular à linha de costa, sentido NW-SE.

Figure 6. GPR profile 1 (antenna 200MHz). A) Radarfacies identified: shallow marine (RF-1), shallow marine/beach reworked by fluvial system of Urussanga River (RF-2), followed by wind capping represented by sand sheets (RF-3); B) Paleochannel detail with filling radarfacies; C) Interpretation of filling radarfacies; D) Location of the section performed perpendicular to the coastline (NW-SE direction). 


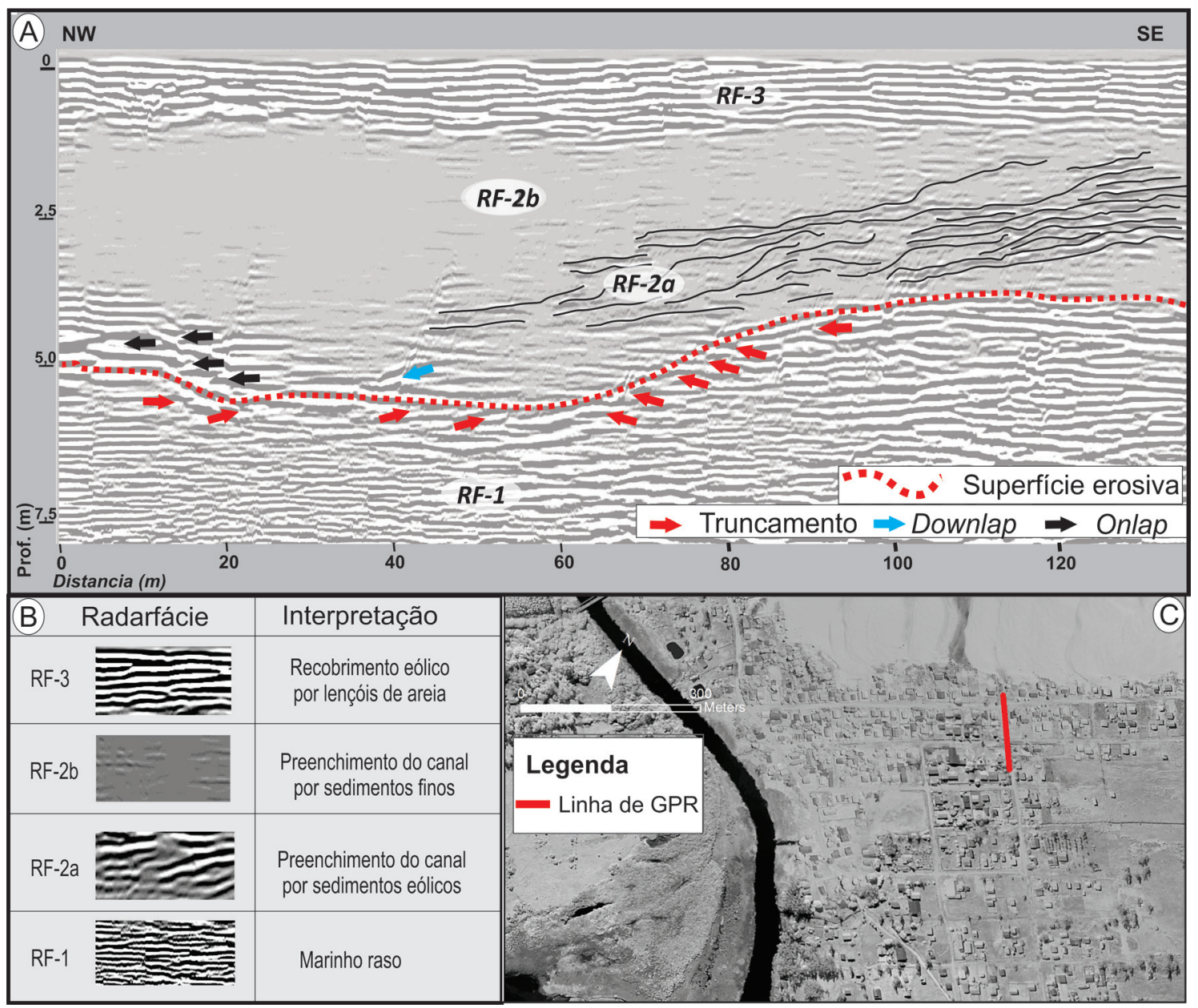

Figura 7. Seção de GPR 2 (antena de 200 MHz). A) Radarfácies e superfície erosiva configurando um paleocanal; B) Interpretação das radarfácies; C) Localização da seção realizada perpendicular à linha de costa (sentido NW-SE).

Figure 7. GPR profile 2 (antenna $200 \mathrm{MHz}$ ). A) Radarfacies and erosive surface configuring a paleochannel; B) Radarfacies interpretation; C) Location of de section performed perpendicular to the coastline (NW-SE direction).

\section{Conclusões}

A utilização das duas técnicas de investigação, de superfície e de subsuperfície, permitiu interpretar as características evolutivas em escalas multitemporais da barreira holocênica do litoral sul de Jaguaruna.

Para a escala temporal mais recente, o uso de técnicas de geoprocessamento foi importante para identificar feições morfológicas de superfície relevantes para caracterização evolutiva da barreira costeira, além de monitorar o comportamento dessas feições em escala decadal (72 anos).

Os mapeamentos geológicos e geomorfológicos auxiliaram na definição das principais unidades deposicionais e feições morfológicas da barreira holocênica. A compreensão dessas características se constituiu numa imprescindível ferramenta de interpretação paleogeográfica da região.

O sistema eólico deste setor está em processo de estabilização. Esse processo fica evidente ao analisar as fotografias aéreas pretéritas, as quais expõem o aumento da vegetação sobre a barreira, e consequente diminuição das dunas móveis.

Os perfis geofísicos permitiram visualizar a arquitetura deposicional e a estratigrafia dos depósitos em subsuperfície, o qual revelou um comportamento regressivo da barreira nesse setor. A influência do Rio Urussanga ao longo da progradação retrabalhou os depósitos marinho raso e praial, e não possibilitou conservar os registros clássicos de barreiras regressivas. Entretanto, outras características, tanto em superfície como em subsuperfície, proporcionaram concluir o comportamento da barreira.

Os dados obtidos com o GPR também expuseram a presença de paleocanais em subsuperfície e a interdigitação entre depósitos aluviais e marinhos. Esta interdigitação evidencia a influência do Rio Urussanga na evolução da barreira.

Agradecimentos Os autores agradecem à Coordenação de Aperfeiçoamento de Pessoal de Nível Superior (CAPES) e ao Conselho Nacional de Desenvolvimento Científico e Tecnológico (CNPq) pelo apoio financeiro. 


\section{Referências}

Alvares, C.A., Stape, J.L., Sentelhas, P.C., Gonçalves, J.L.M. \& Sparovek, G. 2014. Köppen's climate classification map for Brazil. Meteorologische Zeitschrift, 22: 711728.

Angulo, R. J.; Lessa, G. C. \& Souza, M. C., 2006. A critical review of mid-to late-Holocene sea-level fluctuations on the eastern Brazilian coast line. Quaternary Science Reviews. 25, 486-506.

Araújo, C.E.S., Franco, D., Melo, E. \& Pimenta, F. 2003. Wave regime characteristics of the southern Brazilian coast. International Conference on Coastal and Port Engineering in Developing Countries, COPEDEC VI, Colombo, Sri Lanka. Proceedings... Paper 97. CD-ROM.

Barboza, E.G. \& Rosa, M.L.C.C. 2014. Indicadores geológicos e geomorfológicos de setores em erosão na costa do Rio Grande do Sul. In: César Goso. (Org.). Nuevas miradas a la problemática de los ambientes costeros. Ed. Montevideo: DIRAC - Facultad de Ciencias, 2014, v. 1, p. 83-98.

Barboza, E.G., Dillenburg, S.R., Rosa, M.L.C.C., Tomazelli, L.J. \& Hesp, P.A. 2009. Ground-penetrating radar profiles of two Holocene regressive barriers in southern Brazil. Journal of Coastal Research, SI 56: 579-583.

Barboza, E.G., Rosa, M.L.C.C., Dillenburg, S.R., Tomazelli, L.J. \& Ayup-Zouain, R.N. 2011a. Comportamento regressivo/transgressivo da linha de costa na bacia de Pelotas durante o Holoceno médio e tardio. In: López, R.A \& Marcomini, S.C. (Ed.). Problemática de Los Ambientes Costeros. Buenos Aires, Croquis, p. 15-30.

Barboza, E.G., Rosa, M.L.C.C., Hesp, P.A., Dillenburg, S.R., Tomazelli, L.J. \& Ayup-Zouain, R.N. 2011b. Evolution of the Holocene Coastal Barrier of Pelotas Basin (Southern Brazil) - a new approach with GPR data. Journal of Coastal Research, SI 64: 646-650.

Barboza, E.G., Rosa, M.L.C.C. Dillenburg, S.R. \& Tomazelli, L.J. 2013. Preservation Potential of Foredunes in the Stratigraphic Record. Journal of Coastal Research, SI 65:1265-1270.

Barboza, E.G., Rosa, M.L.C.C., Dillenburg, S.R., Biancini Da Silva, A. \& Tomazelli, L.J. 2014a. Stratigraphic analysis applied on the recognition of the interface between marine and fluvial depositional systems. Journal of Coastal Research, SI 70: 205-210.

Barboza, E.G., Rosa, M.L.C.C., Ayup-Zouain, R.N., Gruber, N.L.S., Martins, E.M., Rockett, G.C. \& Cristiano, S.C. 2014b. Comportamento da Barreira Costeira Holocênica ao Sul do Cabo de Santa Marta (Bacia de Pelotas). In: CONGRESSO BRASILEIRO DE GEOLOGIA, 47, 2014. Anais..., Salvador, p. 1818-1818.

Barboza, E.G., Rosa, M.L.C.C. \& Caron, F. 2014c. Metodologia de Aquisição e Processamento em Dados de Georradar (GPR) nos Depósitos Quaternários da Porção Emersa da Bacia de Pelotas. In: SIMPÓSIO BRASILEIRO DE GEOFÍSICA, 6, 2014, Resumos Expandidos, Porto Alegre, v. 1, p. 1-6.

Biancini da Silva, A. 2011. Análise estratigráfica da barreira transgressiva holocênica na região da Lagoa do
Sombrio, SC. Porto Alegre, 68p. Dissertação de Mestrado, Programa de Pós-graduação em Geociências, Instituto de Geociências, Universidade Federal do Rio Grande do Sul.

Biancini da Silva, A. 2016. A herança geológica, a geomorfologia e a estratigrafia da barreira complexa do Passo de Torres - Planície costeira sul catarinense. Porto Alegre. 192p. Tese de Doutorado, Programa de Pós-Graduação em Geociências, Instituto de Geociências, Universidade Federal do Rio Grande do Sul.

Biancini da Silva, A., Barboza, E.G., Rosa, M.L.C.C. \& Dillenburg, S.R. 2014. Meandering Fluvial System Influencing the Evolution of a Holocene Regressive Barrier in Southern Brazil. Journal of Coastal Research, SI 70: 687-692.

Bitencourt, V.B. 2015. Geomorfologia e Arquitetura Deposicional de Uma Planície de Cordões Litorâneos Lacustre, Litoral Norte do RS - Brasil. Porto Alegre. 76p. Dissertação de Mestrado, Programa de Pós-Graduação em Geociências, Instituto de Geociências, Universidade Federal do Rio Grande do Sul.

Boyd, R., Dalrymple, R.W. \& Zaitlin, B.A. 1992. Classification of clastic coastal depositional environments. Sedimentary Geology, 80: 139-150

Calliari, L.J., Pereira, P.S., De Oliveira, A.O. \& Figuereido, S.A. 2005. Variabilidade das dunas frontais no litoral norte e médio do Rio Grande do Sul, Brasil. Gravel, 3: $15-30$.

Caron, F. 2014. Estratigrafia e evolução da barreira holocênica na região costeira de Santa Vitória do Palmar, Planície Costeira do Rio Grande do Sul, Brasil. Porto Alegre. 172p. Tese de Doutorado, Programa de Pós-Graduação em Geociências, Instituto de Geociências, Universidade Federal do Rio Grande do Sul.

Curray, J.R. 1964. Transgressions and regressions. In: Miller, R.L. (Ed.), Papers in Marine Geology. Macmillan, New York, p. 175-203.

Davis, J.L. \& Annan, A.P. 1989. Ground-penetrating radar for high-resolution mapping of soil and rock stratigraphy. Geophysical Prospecting, 37(5): 531-551.

Davis, R.A. \& Hayes, M.O. 1984. What is a wave dominated coast? Marine Geology, 60: 313-329.

Dillenburg, S.R. 1994. A Laguna de Tramandaí: evolução geológica e aplicação do método geocronológico da Termoluminescência na datação de depósitos. Porto Alegre. 194p. Tese de Doutorado, Programa de Pós-Graduação em Geociências, Instituto de Geociências, Universidade Federal do Rio Grande do Sul.

Dillenburg, S.R. \& Hesp, P.A. 2009. Geology and Geomorphology of Holocene Coastal Barriers of Brazil. 1. ed. Heidelberg: Springer, v. 107, 380p.

Dillenburg, S.R. \& Barboza, E.G. 2014. The Dip and Strike-Fed Sandy Coast of Southern Brazil. In: Martini, I.P. \& Wanless H.R. (eds.). Sedimentary Coastal Zones from High to Low Latitudes: Similarities and Differences. Geological Society, London, Special Publications, p. 333-352.

Dillenburg, S.R., Roy, P.S., Cowell, P.J. \& Tomazelli, L.J. 2000. Influence of Antecedent Topography on Coastal Evolution as Tested by the Shoreface Translation-Barrier Model. Journal of Coastal Research, 
16(1): 71-81.

Dillenburg, S.R., Esteves, L.S. \& Tomazelli, L.J. 2004. A critical evaluation of coastal erosion in Rio Grande do Sul, Southern Brazil. Anais Academia Brasileira de Ciências, 76(3): 611-623.

Dillenburg, S.R., Tomazelli, L.J., Hesp, P.A., Barboza, E.G., Clerot, L.C.P. \& Silva, D.B. 2006. Stratigraphy and evolution of a prograded transgressive dunefield barrier in southern Brazil. Journal of Coastal Research, SI 39: 132-135.

Dillenburg, S.R., Barboza, E.G., Tomazelli, L.J., Hesp, P.A., Clerot, L.C.P. \& Ayup-Zouain, R.N. 2009. The Holocene coastal barriers of Rio Grande do Sul. In: Dillenburg, S.R. \& Hesp, P.A. (Ed.). Geology and Geomorphology of Holocene Coastal Barriers of Brazil. Lecture Notes in Earth Sciences, 107, 53-91.

Dillenburg, S.R., Barboza, E.G., Hesp, P.A. \& Rosa, M.L.C.C. 2011. Ground Penetrating Radar (GPR) and Standard Penetration Test (SPT) records of a regressive barrier in southern Brazil. Journal of Coastal Research, SI 64: 651-655.

Dillenburg, S.R., Barboza, E.G., Tomazelli, L.J., Rosa, M.L.C.C. \& Maciel, G.S.2013. Aeolian Deposition and Barrier Stratigraphy of the Transition Region between a Regressive and a Transgressive Barrier: an example from Southern Brazil. Journal of Coastal Research, 65: 464-469.

Dillenburg, S.R., Barboza, E.G., Hesp, P.A., Rosa, M.L.C.C., Angulo, R.J., Souza, M.C., Giannini, P.C.F. \& Sawakuchi, A.O. 2014. Discussion: "Evidence for a transgressive barrier within a regressive strandplain system: implications for complex response to environmental change" by Hein, et al. (2013), Sedimentology, 60: 469-502. A transgressive barrier at Pinheira, Southern Brazil around 3 ka? Sedimentology, 61: 22052212.

Dillenburg S.R., Barboza E.G., Rosa M.L.C.C., Caron F., Sawakuchi A.O. 2017. The complex prograded Cassino barrier in southern Brazil: Geological and morphological evolution and records of climatic, oceanographic and sea-level changes in the last 7-6 ka. Marine Geology, 390:106-119.

Fisher, W.L. \& McGowen, J.H. 1969. Depositional systems in the Wilcox Group (Eocene) of Texas and their relation to the occurrence of oil and gas. American Association of Petroleum, Geologist, Bulletin, 53(1): 30-54.

Fornari, M., 2010. Evolução sedimentar holocênica da retrobarreira na região de Jaguaruna-Laguna, Santa Catarina. São Paulo. 290p. Tese de doutorado, Programa de Pós-Graduação em Geologia Sedimentar, Universidade de São Paulo.

Giannini, P.C.F. 1993. Sistemas Deposicionais no Quaternário Costeiro entre Jaguaruna e Imbituba, Santa Catarina. São Paulo. 475p. Tese de Doutorado, Programa de Pós-Graduação em Geologia Sedimentar, Universidade de São Paulo.

Giannini, P.C.F. \& Suguio, K. 1994. Diferenciação entre gerações de depósitos eólicos quaternários na costa centro-sul de Santa Catarina. In: CONGRESSO BRASILEIRO DE GEOLOGIA, 38, 1994, Balneário Cambo- riú. Resumos Expandidos... Balneário Camboriú, SBG, v.1, p.402-403.

Hein, C.J., Fitzgerald, D.M., Cleary, W.J., Albernaz, M.B., De Menezes, J.T. \& Klein, A.H.F. 2013. Evidence for a transgressive barrier within a regressive strandplain system: Implications for complex coastal response to environmental change. Sedimentology, 60: 469-502.

Hesp, P.A. 2000. Coastal sand dunes: form and function. CDVN Technical Bulletin 4: 1-28

Hesp, P.A. 2004. Coastal dunes in the tropics and temperate regions: location, formation, morphology and vegetation processes. In: Martinez, M.L. \& Psuty, N.P. (Ed.) Coastal dunes, ecology and conservation. Springer-Verlag, Heidelberg, p. 29-49.

Hesp, P.A. 2006. Sand beach ridges: Definition and re-definition. Journal Coastal Research, SI 39: 72-75.

Hesp, P.A. \& Thom, B.G. 1990. Geomorphology and evolution of transgressive dunefields. In: Nordstrom, K.F., Psuty, N.P., Carter, R.W.G. (Ed.) Coastal dunes: processes and morphology. John Wiley \& Sons, Chichester, p. 253-288.

Hesp, P.A., Castilhos, J.A., Silva, G.M., Dillenburg, S., Martinho, T.C., Aguiar, D., Fornari, M. \& Antunes, G. 2007. Regional wind fields and dunefield migration, southern Brazil. Earth Surface Processes and Landforms, 32(4): 561-573.

Horn Filho, N.O., Felix, A., Vieira, C.V. \& Baptista, E.M. de C. 2010. Geologia da planície costeira das folhas Jaguaruna e Lagoa de Garopaba do Sul, SC, Brasil. Revista Discente Expressões Geográficas, 6: 90-110.

Horn Filho, N.O., Schmidt, A.D., Benedet, C., Neves, J., Pimenta, L.H.F., Paquette, M., Alencar, R., Silva, W.B., Villela, E., Genovez, R. \& Santos, C.G. 2014. Estudo Geológico dos Depósitos Clásticos Quaternários Superficiais da Planície Costeira de Santa Catarina, Brasil. Gravel, 12(1): 41-107.

Leal, R. A., Barboza, E. G., Bitencourt, V. J. B., Biancini, A. \& Manzolli, R. P. 2016. Geological and Stratigraphic Characteristics of a Holocene Regressive Barrier in Southern Brazil: GIS and GPR Applied for Evolution Analysis. Journal of Coastal Research, SI 75: 750-754

Lessa, G., Angulo R.J., Giannini P.C.F. \& Araújo A.D. 2000. Stratigraphy and Holocene Evolution of a Regressive Barrier in South Brazil. Marine Geology, 165(1-4): 87-108.

Lima, L.G., Dillenburg, S.R., Medeanic, S., Barboza, E.G., Rosa, M.L.C.C., Tomazelli, L.J., Dehnhardt, B.A. \& Caron, F. 2013. Sea-level rise and sediment budget controlling the evolution of a transgressive barrier in southern Brazil. Journal of South American Earth Sciences, 42: 27-38.

Martinho, C.T., Giannini, P.C.F. \& Sawakuchi, A.O. 2006. Morphological and depositional facies of transgressive dunefields in the Imbituba-Jaguaruna region, Santa Catarina State, Southern Brazil. Journal of Coastal Research, SI 39: 673-677.

Martinho, C.T., Dillenburg, S.R. \& Hesp, P.A. 2008. Mid to late Holocene evolution of transgressive dunefields from Rio Grande do Sul coast, southern Brazil. Marine Geology, 256: 49-64. 
Martins, E.M., Oliveira, J.F., Bitencourt, V.J.B., Scarelli, F.M., Esteves, T., Martinho C.T., Rosa, M.L.C.C. \& Barboza, E.G. 2014. Comportamento Evolutivo da Barreira Costeira junto ao Balneário do Camacho, Jaguaruna/SC. Gravel, 12(1): 109-120.

Miot da Silva, G., Martinho, C.T., Hesp, P.A., Keim, B.D. \& Ferligoj, Y. 2013. Changes in dunefield geomorphology and vegetation cover as a response to local and regional climate variations. Journal of Coastal Research, SI 65: 1307-1312.

Mitchum Jr., R.M., Vail, P.R. \& Sangree, J.B. 1977. Seismic Stratigraphy and Global Changes of Sea Level, Part 6: Stratigraphy interpretation of seismic reflection patterns in deposicional sequences. In: Payton, C.E. (Ed.), Seismic Stratigraphy - Applications to Hydrocarbon Exploration. Tulsa, AAPG, 26, p. 117-133.

Morton, R.A. 1994. Texas Barriers. In: Davis Jr. R.A (Ed.), Geology of Holocene Barrier Island Systems. Berlin. Springer-Verlag, p. 75-114.

Neal, A. 2004. Ground-penetrating radar and its use in sedimentology: principles, problems and progress. Earth Science Reviews, 66: 261-330.

Orselli, L. 1986. Climatologia. In: GAPLAN - SC. Atlas de Santa Catarina. Aerofoto Cruzeiro, Rio de Janeiro, p. 38-39.

Otvos, E.G. 2012. Coastal barriers - Nomenclature, processes, and classification issues. Geomorphology, 139-140: 39-52.

Rosa, M.L.C.C. 2012. Geomorfologia, padrões de empilhamento e potencial de preservação do registro estratigráfico dos sistemas deposicionais costeiros no Quaternário do Rio Grande do Sul. Porto Alegre. 246p. Tese de Doutorado, Programa de Pós-Graduação em Geociências, Instituto de Geociências, Universidade Federal do Rio Grande do Sul.

Rosa, M.L.C.C., Barboza, E.G., Abreu, V.S., Tomazelli, L.J., Dillenburg, S.R., 2017. High frequency sequences in the Quaternary of Pelotas Basin (coastal plain): a record of degradational stacking as a function of longer-term base-level fall. Brazilian Journal of Geology 47(2): 183-207.

Rosa, M.L.C.C., Barboza, E.G., Dillenburg, S.R., Tomazelli, L.J. \& Ayup-Zouain, R.N. 2011. The Rio Grande do Sul (southern Brazil) shoreline behavior during the Quaternary: a cyclostratigraphic analysis. Journal of Coastal Research, SI 64: 686-690.

Roy, P.S.; Cowell, P.J.; Ferland, M.A., \& Thom, B.G. 1994. Wave Dominated Coasts. In: Carter, R.W.G. \& Woodroffe, C.D. (eds.), Coastal Evolution, Late Quaternary shoreline morphodynamics. Cambridge. Cambridge University Press, pp. 121-186.

Manuscrito 612

Editores: Iran S. Corrêa \& Paulo A. Souza
Siegle, E. \& Asp, N.E.2007. Wave refraction and longshore transport patterns along the Southern Santa Catarina coast. Brazilian Journal of Oceanography, 55(2): 109-120.

Tamura, T. 2012. Beach ridges and prograded beach deposits as paleoenvironment records. Earth Science Reviews, 114: 279 - 297.

Tanaka, A.P.B. 2010. Sedimentologia, Cronologia e Dinâmica Progradacional das Planícies Costeiras de Campos Verdes e Ji (Laguna, SC). São Paulo. 113p. Dissertação de Mestrado, Programa de Pós-Graduação em Geologia Sedimentar, Universidade de São Paulo.

Tanner, W.F. 1996. Origin of beach ridges and swales. Marine Geology, 129: 149-161.

Tomazelli, L.J. 1990. Contribuição ao estudo dos Sistemas Deposicionais Holocênicos do Nordeste da Província Costeira do Rio Grande do Sul, com Ênfase no Sistema Eólico. Porto Alegre, 270p. Tese de Doutorado, Programa de Pós-Graduação em Geociências, Instituto de Geociências, Universidade Federal do Rio Grande do Sul.

Tomazelli, L.J. 1994. Morfologia, Organização e Evolução do Campo Eólico Costeiro do Litoral Norte do Rio Grande do Sul, Brasil. Pesquisas, 21(1): 64-71.

Tomazelli, L.J. \& Villwock, J.A. 2000. O Cenozóico no Rio Grande do Sul: Geologia da Planície Costeira. In: Holz, M. \& De Ros, L.F. (eds.). Geologia do Rio Grande do Sul. Porto Alegre, IG/UFRGS, p. 375-406.

Travessas, F.A., Dillenburg, S.R. \& Clerot, L.C.P. 2005. Estratigrafia e evolução da barreira holocênica do Rio Grande do Sul no trecho Tramandaí-Cidreira. Boletim Paranaense de Geociências, 57: 57-73.

Van Overmeeren, R.A. 1998. Radarfacies of unconsolidated sediments in The Netherlands: A radar stratigraphy interpretation method for hydrogeology. Journal of Applied Geophysics, 40: 1-18.

Vieira, C.V., Felix, A., Baptista, E.M.C. \& Horn Filho, N.O. 2009. Paleogeografia da planície costeira das folhas Jaguaruna e Lagoa de Garopaba do Sul, litoral sul do estado de Santa Catarina. Geosul, 24(47): 91-112.

Villwock, J.A., Tomazelli, L.J., Loss, E.L., Dehnhardt, E.A., Horn, N.O., Bachi, F.A. \& Dehnhardt, B.A. 1986. Geology of the Rio Grande do Sul coastal province. In: RABASSA, J. (ed.). Quaternary of South America and Antarctic Peninsula, 4: 79-97.

Villwock, J.A. \& Tomazelli, L.J. 1995. Geologia Costeira do Rio Grande do Sul. Notas Técnicas, 8: 1-45.

Woods, A.J.C. \& Leahy, L.P. 1983. Beach ridges and paleogeography, Central Baja California, Mexico. Physical Geography, 4(3): 167-181. 